\title{
Genome-wide analyses of small non-coding RNAs in streptococci
}

\author{
Nadja Patenge*, Roberto Pappesch, Afsaneh Khani and Bernd Kreikemeyer \\ Institute of Medical Microbiology, Virology, Hygiene and Bacteriology, Rostock University Medical Center, Rostock, Germany
}

\section{OPEN ACCESS}

Edited by:

Marie-Frédérique Lartigue, Université François Rabelais de Tours,

France

Reviewed by:

Angela Pearson,

Institut National de la Recherche Scientifique-Institut Armand-Frappier,

Canada

Zhipeng Qu,

The University of Adelaide, Australia

*Correspondence: Nadja Patenge, Institute of Medical Microbiology, Virology, Hygiene and Bacteriology, Rostock University Medical Center, Schillingallee 70, 18057 Rostock,

Germany

nadja.patenge@med.uni-rostock.de

Specialty section

This article was submitted to

RNA,

a section of the journal

Frontiers in Genetics

Received: 17 March 2015 Accepted: 08 May 2015

Published: 20 May 2015

Citation:

Patenge N, Pappesch R, Khani A and Kreikemeyer B (2015)

Genome-wide analyses of small non-coding RNAs in streptococci.

Front. Genet. 6:189.

doi: 10.3389/fgene.2015.00189
Streptococci represent a diverse group of Gram-positive bacteria, which colonize a wide range of hosts among animals and humans. Streptococcal species occur as commensal as well as pathogenic organisms. Many of the pathogenic species can cause severe, invasive infections in their hosts leading to a high morbidity and mortality. The consequence is a tremendous suffering on the part of men and livestock besides the significant financial burden in the agricultural and healthcare sectors. An environmentally stimulated and tightly controlled expression of virulence factor genes is of fundamental importance for streptococcal pathogenicity. Bacterial small non-coding RNAs (sRNAs) modulate the expression of genes involved in stress response, sugar metabolism, surface composition, and other properties that are related to bacterial virulence. Even though the regulatory character is shared by this class of RNAs, variation on the molecular level results in a high diversity of functional mechanisms. The knowledge about the role of sRNAs in streptococci is still limited, but in recent years, genomewide screens for sRNAs have been conducted in an increasing number of species. Bioinformatics prediction approaches have been employed as well as expression analyses by classical array techniques or next generation sequencing. This review will give an overview of whole genome screens for sRNAs in streptococci with a focus on describing the different methods and comparing their outcome considering sRNA conservation among species, functional similarities, and relevance for streptococcal infection.

Keywords: sRNA, Streptococcus, array, RNAseq, NGS, virulence, gene regulation, transcriptome

\section{Introduction}

Bacterial small non-coding RNAs (sRNAs) play a fundamental role in the regulation of virulence factor genes in pathogenic bacteria (Papenfort and Vogel, 2010). Overall, there is still a lot more information available about riboregulators in Gram-negative model organisms, e.g., Escherichia coli, Salmonella, and Helicobacter pylori, compared to Gram-positive pathogens. The importance of sRNAs for pathogenesis in streptococci has been already acknowledged, but intensive functional studies are still missing. As a first step, a number of genome wide screenings for sRNAs have been performed in streptococci. Before we describe the sRNA analyses efforts in different species, we would like to introduce the significance of streptococci as causative agent of disease in human and livestock, focusing on those species, which have been subjected to sRNA screening.

According to Bergey's Manual of Systematic Bacteriology streptococci are one of 17 genera belonging to the facultatively anaerobic Gram-positive cocci (Facklam, 2002). The genus Streptococcus includes a large number of individual species (>100). Typing and differentiation 
historically relied on haemolytic phenotypes during growth of the species on blood agar plates, designating isolates as $\beta$-hemolytic and non- $\beta$-hemolytic. This classification system was introduced by work of Schottmüller and Brown in the early 1900 [reviewed in (Facklam, 2002)]. A more refined and sophisticated classification was introduced by pioneering work of Rebecca Lancefield at Rockefeller University New York in 1933. She demonstrated specific carbohydrate "group" antigens to be discriminative in a serological typing scheme (Lancefield, 1933). The current classification and revision of the Streptococcus genus is based on $16 \mathrm{~S}$ rRNA gene sequencing.

Prominent streptococcal species belonging to the B-hemolytic group are Streptococcus pyogenes, S. agalactiae, S. dysgalactiae, S. equi, S. canis and S. iniae. S. pneumonia, S. suis, S. intermedius, $S$. mutans, and species of the S. salivarius-, S. anginosus-, and $S$. mitis-group are typically non- $\beta$-hemolytic (Facklam, 2002; Krzysciak et al., 2013). Humans and animals are major hosts for the above mentioned species, which occur mainly as physiological flora of skin, throat, upper respiratory tract, and intestine of their hosts. Some of them are rather opportunistic pathogens, thriving only in the background of ill or immunocompromised humans and animals. The pathogenic streptococcal species can be further classified into three distinguishable groups: common pathogenic streptococci causing infections in humans, opportunistic commensals, and zoonosis pathogens. The latter can cause disease in animals and humans or are transmitted as primarily animal pathogens to humans during farming and otherwise intensive contacts (Krzysciak et al., 2013). S. mutans, S. intermedius, S. canis, S. sanguinis, S. salivarius, and S. gordonii are opportunistic commensals causing caries, spleen, and brain abscesses, soft tissue and urinary tract infections, bacteremia, bone infections, pneumonia, meningitis, sepsis, and endocarditis, respectively. S. suis is currently the most prominent zoonosis pathogen among the streptococci, causing severe invasive, and mostly lethal infections in swine and humans (Fulde and Valentin-Weigand, 2013). The following part gives brief introductions into those streptococcal species for which studies and global screens for sRNAs have been performed.

\section{Streptococcus pneumoniae}

This species can be found as commensal and colonizer of the human nasopharynx, however, under favorable conditions can cause local infections which can easily progress into life-threatening invasive diseases (most common: bacteremia and meningitis). Between 10 and $20 \%$ of adults and up to $40 \%$ of children are colonized by pneumococci, most likely building the basic pathogen reservoir for transmission and causing community acquired pneumonia. According to WHO 1.2 million infants aged below 5 -years die due to pneumonia per year (data from the CDC Atlanta). Next to this infantile risk group, people aged above 65-years bear a higher risk for pneumococcal infections, which is a clear hint for a correlation of declining immune fitness and susceptibility toward peumococcal infection. A major virulence factor is the polysaccharide capsule, allowing serological distinction of over 90 capsule serotypes. Seven, 13, and 23 -valent capsule polysaccharide based conjugate vaccines are available and proved to be very efficient, however, serotype displacement in colonization phenotypes and in particular rising antibiotic resistance rates in this naturally competent species highlight pneumococci as dangerous pathogens. For the interested reader a recent and excellent review of pneumococci and their pathogenesis was published by Gamez and Hammerschmidt (2012).

\section{Streptococcus pyogenes}

Streptococcus pyogenes (group A streptococci according to Lancefield scheme; GAS) is an exclusively human pathogen responsible for an extraordinary array of different diseases. S. pyogenes infections in immunocompetent hosts range from mild, mostly locally restricted, and self-healing diseases (pharyngitis, impetigo, pyoderma) affecting mainly skin and mucosal membranes (Cunningham, 2008; Walker et al., 2014) to severe and life-threatening invasive disease manifestations, e.g., necrotizing fasciitis and streptococcal toxic shock syndrome. The latter are associated with high morbidity and mortality rates in affected patients. The significance of $S$. pyogenes diseases is underscored by the large global burden to the national health care systems. Data compiled in 2005 by Bisno and colleagues and Carapetis and colleagues revealed 616 million cases of pharyngitis, 111 million cases of pyoderma, and at least 517.000 fatalities due to invasive diseases and sequelae (Bisno et al., 2005; Carapetis et al., 2005; Ralph and Carapetis, 2013). Sequelae manifested after non-treated primary infections comprise rheumatic heart disease and glomerulonephritis, both severely affecting underdeveloped countries and poor communities with limited access to antimicrobial chemotherapeutics. S. pyogenes is still fully sensitive toward penicillin. However, increasing numbers of macrolide resistant strains are of concern (Logan et al., 2012). The virulence factor repertoire, function of many virulence factors in the pathogenesis of this species, action of transcriptional regulators, two-component regulatory systems and their networking activities, as well as pinpointing molecular evolutionary events (like IndDels) leading to increased fitness and spread of certain globally disseminated strains have all been recently reviewed (Kreikemeyer et al., 2003; Hondorp and McIver, 2007; McIver, 2009; Fiedler et al., 2010; Patenge et al., 2013; Walker et al., 2014).

\section{Streptococcus mutans}

Streptococcus mutans is the most prominent species in the context of caries etiology. This species is a potent biofilm former and its sugar metabolism releases acids which act on dentin to form the typical carries-associated cavities in hosts, who do not practice proper oral hygiene. Many $S$. mutans virulence factors involved in the biofilm phenotype have been characterized in detail (Krzysciak et al., 2013). This streptococcal species does also efficiently survive in human blood and is thus involved in cases of infective endocarditis, where bacteria are part of massive vegetations on heart valve regions where blood clots rich in platelets and fibrinogen cover damaged areas. The high burden on human health and the financial strain on the healthcare systems due to caries, bring these bacteria in the focus of 
scientific attention, which includes discovery, and functional characterization of sRNAs.

\section{Streptococcus suis and Other Zoonotic Streptococci}

Four major species are considered zoonosis pathogens among the streptococci, including S. canis, a resident of the microflora of domestic carnivores, S. equi sp. zooepidemicus, an opportunistic pathogen in cats, rodents, minks, monkeys, and seals, $S$. iniae, an invasive fish pathogen, and S. suis, a major porcine pathogen occurring worldwide (Fulde and Valentin-Weigand, 2013). S. suis is probably the most important zoonosis pathogen, which emerged in the media spotlight after totally unexpected severe invasive disease with toxic shock likesyndrome outbreaks reported in China, 2005 (Yu et al., 2006). A serotype two strain was identified as causative agent and new emerging type which contained a previously unknown pathogenicity island. These pathogens are directly transmitted from swine to their human host during intensive contacts of farmers with their lifestock, eating of high risk dishes, like undercooked meat, blood and intestine of animals, mainly in poor low-income, and underdeveloped countries like Southeast Asia (Fulde and Valentin-Weigand, 2013). In swine, sepsis, meningitis, arthritis, and pneumonia caused by $S$. suis lead to tremendous economic losses. In humans, meningitis is the major disease that is diagnosed after S. suis infection.

\section{Streptococcus agalactiae}

Streptococcus agalactiae (group B streptococci according to Lancefield scheme, GBS) is an important human pathogen which is found in the urogenital tract and the lower gastrointestinal tract. Up to $40 \%$ of healthy women at reproductive age are colonized with these bacteria which are apparently part of the normal flora. However, exactly this colonization site is a sincere risk for pathogen transmission to neonates during labor and birth canal passage (Dando et al., 2014). Infected neonates can develop so called early onset disease, including sepsis, pneumonia, and meningitis. This occurs in about 5000 newborns in the US annually (Gibbs et al., 2004). Early onset diseases are associated with a $5 \%$ mortality rate. In underdeveloped countries neonate infection and killing rates are thought to be much higher, since inefficient health care systems do not provide effective mother pre-screening programs, monitoring, intensive care, and treatment options (Johri et al., 2013). Moreover, due to a majority of home births, the actual death toll numbers cannot be taken into consideration in the official statistics. Manifestation of GBS disease in elderly and immunocompromised hosts, associated with high morbidity and mortality rates, include skin and soft tissue infections, bacteremia, pneumonia, osteomyelitis, and infections of the urinary tract (Edwards et al., 2005). Unlike $S$. pyogenes, S. agalactiae can infect ruminants causing mastitis (Keefe, 1997). Many S. agalactiae virulence factors have quite some structural and functional similarities with their counterparts expressed by $S$. pyogenes and are mostly well characterized (Lindahl et al., 2005; Kreikemeyer et al., 2011). Moreover, transcriptional regulation of $S$. agalactiae virulence genes resembles mechanisms seen in other streptococcal species, a fact recently reviewed (Rajagopal, 2009; Patenge et al., 2013).

\section{sRNAs in Bacteria}

The actual virulence of the streptococcal species described above depends on a set of specific virulence factors, which first allows the bacteria to colonize and invade the host organism and then to survive and proliferate in the hostile environment. In the course of a successful infection, bacteria have to respond to the challenging conditions at the infectious site and to the host defense mechanisms by the coordinated expression of the appropriate virulence factor genes. Bacterial adaptation to environmental changes through the regulation of gene expression has been studied intensively since the middle of the 20th century. The research focus was on the role of proteins influencing the activity of the transcriptional machinery including transcription factors, two component systems (TCSs), and sigma factors. During the first decade of this century, it became clear that RNAs serve as important regulatory molecules in eukaryotes as well as in prokaryotes. Among them, miRNAs, sRNAs, long noncoding RNAs, and riboswitches have been investigated in all three domains of life.

In bacteria, the importance of sRNAs as a distinct class of gene regulators is well established by now. First, the high number of regulatory RNAs that was found in many bacteria was unexpected (Brantl, 2009; Narberhaus and Vogel, 2009; Waters and Storz, 2009). Soon, it became evident that many diverse processes were controlled by bacterial sRNAs, including stress response, sugar metabolism, biofilm formation, and surface composition (Vanderpool and Gottesman, 2005; Gottesman et al., 2006; Heidrich et al., 2006; Gorke and Vogel, 2008; Gogol et al., 2011; Sharma et al., 2011; Mika and Hengge, 2013). Moreover, several sRNAs with housekeeping functions were identified, which are highly conserved throughout bacteria, e.g., tmRNA, 6S RNA, and RNase P (Brantl, 2009). In pathogenic bacteria, regulatory RNAs are involved in host-microbe interactions and lifestyle adaptation by controlling virulence gene expression and the general stress response (Papenfort and Vogel, 2010; Caldelari et al., 2013).

There are different classes of regulatory RNAs covering distinct modes of function. On the one hand, cis-acting RNAs are contained within $5^{\prime}$-untranslated regions (5'-UTRs) of coding transcripts. Usually, the secondary structure of the respective $5^{\prime}$-UTR is changed in response to an environmental stimulus, e.g., temperature in the case of RNA-thermometers or ligand binding in the case of riboswitches. As a consequence, translation initiation is inhibited or premature transcription termination occurs (Klinkert and Narberhaus, 2009; Bastet et al., 2011; Serganov and Nudler, 2013).

Another group of sRNAs is transcribed independently and functions via cis- or trans-antisense base pairing. Cis-acting antisense sRNAs are encoded on the opposite strand of their respective target gene. The high sequence complementarity to their target RNA leads to a very strong and specific binding. A typical example is the toxin-antitoxin system type I in bacteria, in which a cis-acting sRNA represses the expression of a toxic hydrophobic peptide gene by base-pairing (Brantl, 2012). In 
several studies, a high level of antisense transcription was detected in a variety of bacteria, with a subsequent processing by RNAse III occurring predominantly in Gram-positive bacteria (Lasa et al., 2012; Lybecker et al., 2014).

In contrast, trans-acting sRNAs are encoded in a location elsewhere in the genome and show a short and imperfect complementarity to their target RNAs. The consequence is a lower binding strength and target specificity that goes hand in hand with the ability to control more than one target gene. Highly complex regulatory networks are built through the interaction of sRNAs with many different targets (Papenfort and Vogel, 2009). Manifold molecular mechanisms belong to the regulatory repertoire of trans-acting sRNAs. Some act as repressors of translation and/or destabilize mRNA transcripts while others activate and/or stabilize target mRNAs (Frohlich and Vogel, 2009; Podkaminski and Vogel, 2010; Thomason and Storz, 2010; Storz et al., 2011).

To understand how sRNAs are able to regulate a multitude of different target mRNAs the binding regions need to be investigated. Interference with translation of target mRNAs is not restricted to the ribosome binding site (RBS) and the start codon. In Salmonella, translational repression by binding of GcvB to conserved C/A-rich sequences within but also upstream of the shine-dalgarno sequence of several target mRNAs was detected, indicating that repression is not solely achieved by masking the RBS but also by blocking translational enhancer sequences (Sharma et al., 2007). Furthermore, binding of the sRNA RybB to the $5^{\prime}$ coding region of ompN was also shown to repress translation in Salmonella (Bouvier et al., 2008). Similarly, in Bacillus subtilis, binding of SR1 to a region 100 nucleotides downstream from the $a h r C$ RBS inhibits translation initiation by induction of structural changes downstream from the RBS (Heidrich et al., 2007). A distinct mechanism has been described for the CRISPR RNAs in $S$. pyogenes, which are involved in RNA maturation and work in concert with a specialized protein family, the Cas-proteins. In this adaptive bacterial immune system, foreign DNA is recognized and eliminated. Therefore, the presence of complementary regions in the RNA is necessary to induce specific processing of the target sequences (Deltcheva et al., 2011).

Regulation by sRNAs is not restricted to mRNA binding. There are many examples in the literature where sRNA molecules bind to and influence proteins, typically by sequestration of a factor involved in transcription or translation (Babitzke and Romeo, 2007). The function of many sRNAs in Gramnegative bacteria and in some Gram-positive species is dependent on the molecular chaperon $\mathrm{Hfq}$ (host factor Q-beta phage). The Sm-like protein is involved in RNA folding and facilitates sRNA-mRNA interaction (Peng et al., 2014). Not all sRNAs of a given species require Hfq for their function and in some model organisms, including streptococci, no $h f q$ homologue could be detected at all (Rieder et al., 2012).

Recently, a further level of complexity in gene regulation could be demonstrated in two Gram-positive pathogens. In Enterococcus faecalis and Listeria monocytogenes, eut genes are responsible for ethanolamine utilization. A riboswitch binding to vitamin $\mathrm{B}_{12}$ regulates the transcription of an sRNA. In the absence of vitamin $B_{12}$, the sRNA is synthesized and binds to the two-component system response regulator EutV. Sequestration of EutV inhibits the ethanolamine dependent activation of eut gene expression (DebRoy et al., 2014; Mellin et al., 2014). This two-step regulatory mechanism involving a riboswitch that controls the expression of a sRNA in combination with a two-component system, allows the integration of two environmental signals: the presence of vitamin $\mathrm{B}_{12}$ and of the substrate ethanolamine. Consequently, only in the presence of both molecules required for ethanolamine utilization, eut gene expression is initiated.

To fully understand bacterial pathogenesis, virulence gene regulation by sRNAs has to be taken into account. In recent years, many screens have been conducted for the identification of sRNAs in Gram-positive bacteria. For a subset of these sRNAs, the respective targets could be verified experimentally (Mraheil et al., 2010; Brantl and Bruckner, 2014). The knowledge about the regulatory function of sRNAs in streptococci has been summarized in three recent review articles (Le and Charpentier, 2012; Patenge et al., 2013; Miller et al., 2014). Here, an overview will be given of different screening methods that have been applied for the analyses of sRNA expression detection and genome-wide bioinformatics prediction in streptococcal species (Figure 1). If available, examples for the role of sRNAs in virulence related gene expression control will be described.

\section{Streptococcus pneumoniae}

\section{Screening for sRNAs Controlled by the CiaR/H Regulatory System in S. pneumoniae}

A typical feature of sRNAs is the cross-communication with protein-mediated gene expression regulation pathways. In many cases sRNA gene expression is controlled by transcriptional regulators or, vice versa, sRNAs influence the expression of regulator genes. Thus, it is not surprising that the first sRNA genes identified in $S$. pneumoniae were part of the CiaRH two-component regulatory circuit, which is involved in competence and virulence. In a transcriptional mapping study, a direct repeat motif, TTTAAG-N5-TTTAAG, was detected in three promoters that were known to be directly regulated by the response regulator CiaR. CiaR binding to the repeat region was shown in gel-shift assays and the importance of the repeat for transcriptional activation by CiaR was demonstrated by promoter mutation experiments. Subsequently, the $S$. pneumoniae genome was analyzed by motif and pattern searches and 15 promoters were identified that were controlled by CiaR. Of those, the five strongest promoters were found to drive the expression of sRNAs, designated csRNAs (ciadependent sRNAs; Halfmann et al., 2007; Table 1). All five csRNAs showed a high degree of sequence conservation and structural similarity, marked by two stem-loops separated by about 40 unpaired nucleotides. The presence of the respective 


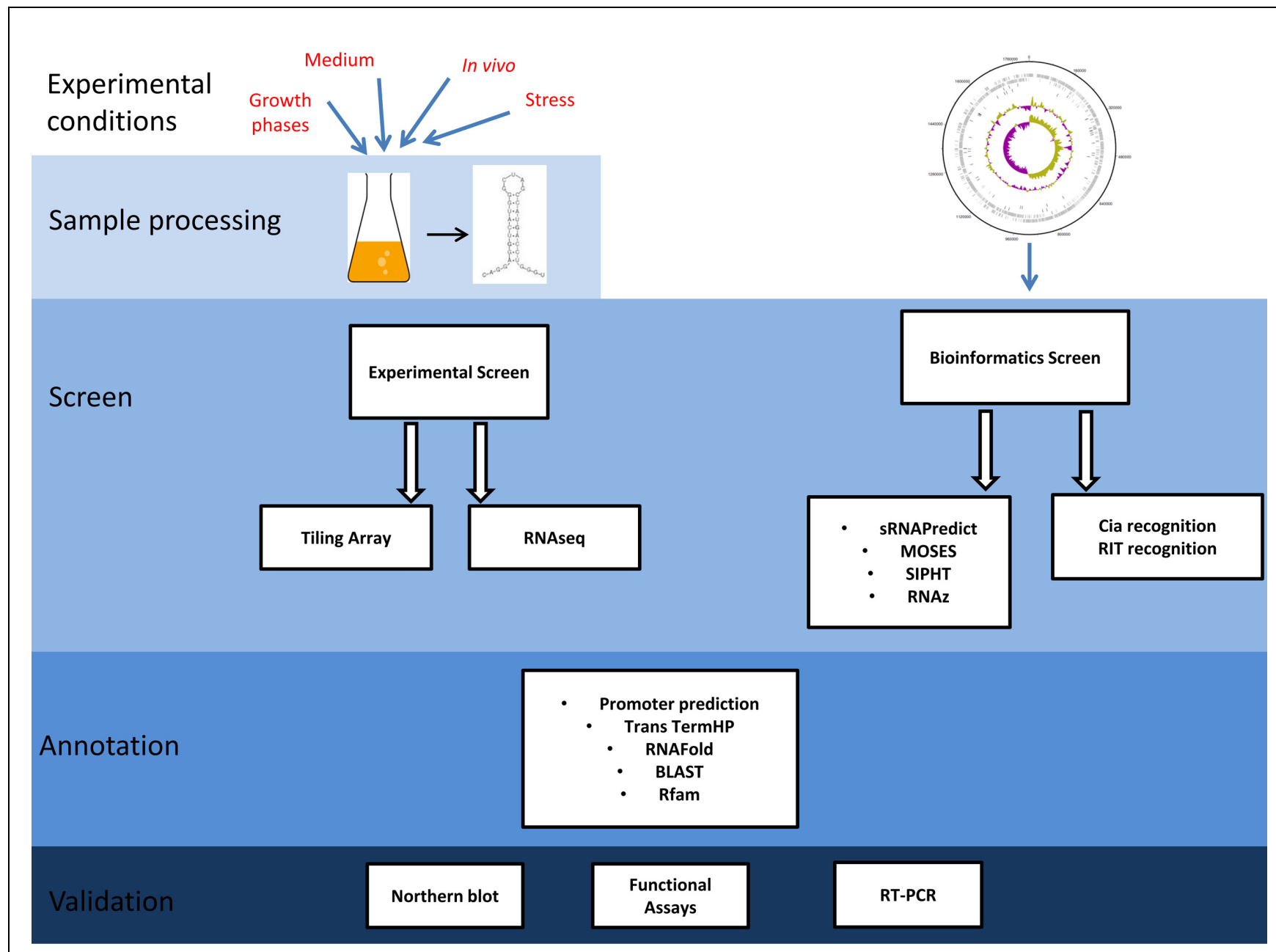

FIGURE 1 | Schematic of the work flow for the experimental and bioinformatics screens used for the detection of small non-coding RNA (sRNAs) in streptococci. Experimental Screens: bacteria were grown under different conditions. Total RNA was prepared and processed by size exclusion and/or enrichment techniques. Samples were reverse transcribed and the resulting cDNA libraries were used for tiling arrays or next generation sequencing (RNAseq). Hybridization signals or sequence reads, respectively, were statistically analyzed for data quality and the expression level was assessed. Transcriptional start sites, sRNA length, orientation, secondary structure, sequence conservation, sRNA function, and potential targets were predicted by additional software tools (BLAST, Basic Local Alignment Search
Tool; Rfam, RNA families database). Finally, likely sRNA candidates were validated by Northern blot or reverse transcription PCR (RT-PCR) and a subset of sRNAs was further characterized by deletion analyses, functional assays, and in vivo infection models. Bioinformatics screens: Fully sequenced reference genomes of the organism of interest were either analyzed using SRNA prediction algorithms (MOSES, modular sequence suite; SIPHT, sRNA identification protocol using high-throughput technology; RNAz, Fast and reliable prediction of non-coding RNAs) or alternatively, known recognition sites for SRNA related proteins were used as a signature to detect novel sRNA candidate genes. Prediction of sRNAs was followed by annotation and validation analogous to the experimental screens.
csRNAs was verified by Northern blot analyses. Deletion analyses revealed that csRNA4 and csRNA5 are involved in autolysis control, whereas the other three csRNAs did not affect autolysis behavior. Competence was not influenced by any of the csRNAs (Halfmann et al., 2007). Within the first loop of the csRNAs1-3, and csRNA5, a CCUCCU motif is conserved, which could serve as an anti-SD sequence, hinting toward inhibition of translational initiation by blocking of ribosome binding. By sequence comparison, csRNAs were detected in other $S$. pneumoniae strains and in closely related streptococci like S. mitis and S. sanguinis (Halfmann et al., 2007).
In a follow-up approach, csRNAs were searched systematically in streptococci: if the ciaRH system was conserved throughout streptococci, cia-dependent sRNAs might be present as well. A BLAST search (Altschul et al., 1990) using the 5 csRNA sequences originally identified in S. pneumoniae, revealed all 5 csRNAs in all $S$. pneumoniae strains tested and some hits with limited similarity in other streptococcal species (Marx et al., 2010). To be able to detect potential csRNAs with a low sequence similarity to the $S$. pneumoniae csRNA sequences, the intergenic regions (IGRs) of 14 streptococcal genomes were screened for CiaR controlled promoters followed by terminators, using motif search, and TransTermHD (Kingsford et al., 2007; 


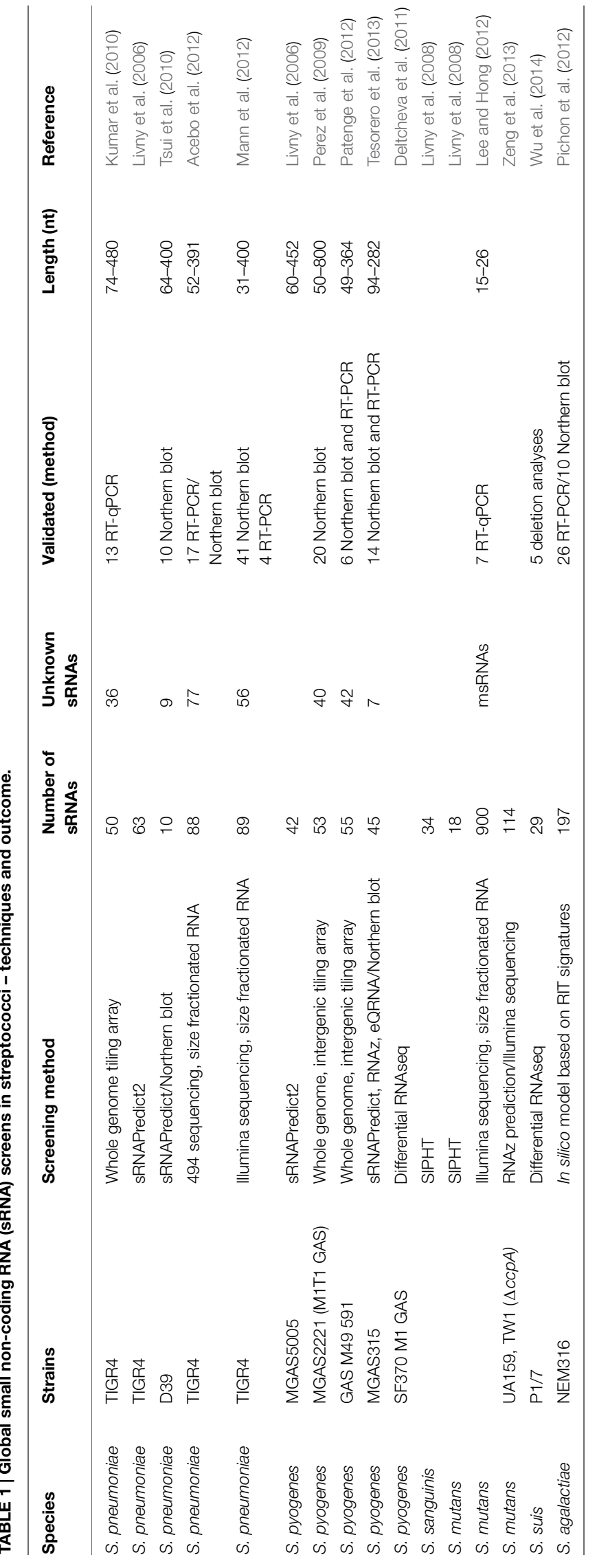

Marx et al., 2010). Fifty eight candidate csRNA genes were predicted, representing 40 different csRNA types. The overall sequence similarity between the various csRNAs was low. Only short sequence stretches of the csRNAs were conserved, including the region consisting of the anti-SD sequence plus antistartcodon and a conserved nonamer, [A/C]UCCUAAA[A/C], located at the $5^{\prime}$ region of the csRNA or following the first stem-loop, respectively. Since the molecular chaperone Hfq is missing in streptococci (Valentin-Hansen et al., 2004), one possible function of this second conserved stretch is a protein binding region for the interaction with an alternative protein. The number of csRNAs in the various species varied from two to six, but each csRNA predicted in one strain could be detected in all other strains by BLAST. The expression of the predicted csRNAs was verified by Northern blot analyses in S. sanguinis, S. mitis, and S. oralis (Marx et al., 2010). In this screen, a high number of Cia-dependent promoters was detected allowing the refinement of the CiaR-binding sequence using WebLogo (Crooks et al., 2004). Based on this information the consensus sequence for CiaR binding was changed to NTTAAGN5-TTTAAG (Marx et al., 2010). Taken together, csRNAs are present in all streptococci but not in unrelated Gram-positive bacteria. While the sequence conservation between csRNA types is limited, all csRNAs seem to belong to the CiaR regulon. The elucidation of the regulatory mechanism of the individual csRNAs will shed light on their role within the $\mathrm{CiaR} / \mathrm{H}$ regulatory circuit.

\section{Global Screenings for sRNAs in S. pneumoniae}

In a bioinformatics sRNA screening using sRNAPredict2, 63 sRNA candidate genes were detected in S. pneumoniae TIGR4 (Livny et al., 2006). The results of this study served as basis of a systematic validation approach in serotype 2 D39 (Tsui et al., 2010). Therefore, a BLAST search was conducted, in which 40 candidate genes were detected with more than $90 \%$ identity to the initially predicted sequences. Northern blot validation confirmed the expression of csRNA1 and of nine novel sRNAs in serotype 2 D39 (Table 1). Five of the sRNA genes showed differential expression dependent on the growth phase or upon stimulation with competence stimulatory peptide (Tsui et al., 2010).

Using whole genome tiling microarrays, 50 sRNAs were identified in S. pneumoniae serotype 4 TIGR4 (Kumar et al., 2010). The overlap with the 63 sRNAs candidates from the data set of the sRNAPredict2 study (Livny et al., 2006) was very low. Only eight sRNAs were detected with both approaches, four of which had been verified before by Northern blot (Tsui et al., 2010). The five csRNAs identified in S. pneumoniae R6 (Halfmann et al., 2007) could be detected in S. pneumoniae TIGR4. The expression of 13 candidate sRNA genes was validated by quantitative reverse-transcriptase PCR (qRT-PCR). All candidate sRNA genes were highly conserved within pneumococcal strains. Twenty five sRNAs were conserved in closely related streptococci (S. mitis, S. gordonii, S. sanguinis) but not in other streptococci (S. pyogenes, S. mutans, S. bovis) and only six sRNA sequences were conserved in other Gram-positive species. Functional predictions for 14 sRNAs were possible 
using the Rfam database (Griffiths-Jones et al., 2003; Nawrocki et al., 2015), whereas for 36 sRNA gene candidates no function could be assigned, which made them likely candidates for novel sRNAs. Eight sequence motifs present in the pneumococcal sRNAs were identified using MEME SUITE (Bailey et al., 2009). Two of the motifs were detected in the five homologs of the csRNAs identified in S. pneumoniae R6 (Halfmann et al., 2007), underlining the conservation of csRNAs in pneumococci. For two motifs no putative function could be predicted by Rfam and the other four motifs were specific for different types of cis-regulatory sRNAs (Kumar et al., 2010).

Another screening for sRNA candidates in S. pneumoniae serotype 4 TIGR4 was performed employing a 454 pyrosequencing approach (Acebo et al., 2012). Total RNA was size-fractionated and 5S rRNA-depleted prior to cDNA library preparation to enrich the sRNA population in the sample. 135 contig sequences were overlapping the $5^{\prime}$-end (57) or the $3^{\prime}$-end (78) of an ORF and a subset of those might represent cis-regulatory RNAs. As candidates for putative sRNAs encoded within an IGR, 88 sequences were identified. Eighteen candidates corresponded with sRNAs detected in the previous TIGR4 tiling array study, six of which had been validated by RT-PCR (Kumar et al., 2010). Of the 63 sRNAs assigned by sRNAPredict2 (Livny et al., 2006), eight candidates were detected in this study (Acebo et al., 2012). Three of those overlapping sRNAs were also present in the tiling array data set (Kumar et al., 2010). From the previously identified five CiaR-dependent sRNAs, csRNA3 and csRNA5 were detected, whereas csRNA1, csRNA2, and csRNA4 appeared to be absent. Due to the high sequence homology of the csRNAs to each other, the authors assumed that sequence reads were incorrectly assigned to csRNA3 during mapping, masking the presence of csRNA1, csRNA2, and csRNA4. Functional prediction using the Rfam database (Griffiths-Jones et al., 2003) led to the assignment of three candidates as housekeeping RNAs (RNase P, tmRNA, and 6S RNA) and eight candidates as cis-regulators, including riboswitches and ribosomal protein gene leader sequences. Seventy seven sRNAs did not show any homology to any known RNA family and were considered novel sRNAs in S. pneumoniae (Acebo et al., 2012). Target prediction using TargetRNA (Tjaden et al., 2006) followed by functional analyses led to the conclusion that srn206 is involved in CSP-dependent competence regulation in S. pneumoniae, probably by interaction with the ComD pathway. From 44 sRNAs $\geq 100 \mathrm{nt}$ in lenght, seven were specific for S. pneumoniae and 37 were conserved in other streptococci, indicating a speciesand genus-specific conservation of pneumococcal sRNAs (Acebo et al., 2012).

TIGR4 and three isogenic TCS mutants were analyzed in a whole-genome RNAseq experiment with the aim to identify sRNAs involved in pneumococcal virulence (Mann et al., 2012). The mutant strains carried mutations in the response regulator genes of the TCSs GRR, Cbpr, and VncR, respectively. Total RNA of each strain was size-fractionated ( $<200 \mathrm{nt}$ ), individually sequenced, and the resulting data were pooled. For the prediction of sRNA genes, a prokaryotic promoter prediction program (University of Groningen) and TransTermHP (Kingsford et al., 2007) were employed. The analysis revealed 89 putative sRNAs.
Of those, 56 were novel and 33 had been identified before in the studies described above. Expression of 41 sRNA candidate genes was verified by Northern blot, four sRNAs were confirmed by RT-PCR, and 10 sRNAs had been confirmed in previous studies. Comparison of the different strains revealed 24 sRNA candidates that were not detectable in the parental TIGR4 strain but were expressed in at least one of the TCS mutant strains. In accordance with the other sRNA screens in pneumococcus, more than $90 \%$ of the identified sRNAs were conserved in $S$. pneumoniae, 11 were conserved amongst streptococci, and 17 amongst other Gram-positive bacteria. A sequence motif search utilizing MEME SUITE (Bailey et al., 2009), revealed five different motifs that were conserved in several sRNA candidates. Sequence analyses using the Rfam database (GriffithsJones et al., 2003) predicted six putative sRNA sequences to be cis-acting riboswitches. In this study, the influence of sRNAs on pneumococcal virulence was studied using a murine model of infection. From the sRNAs that were confirmed by Northern blot, 15 candidates were picked for deletion analyses and eight of the sRNA deletion mutants were attenuated in the progression of sepsis. Furthermore, pathogenesis was investigated by Tn-Seq fitness determination (Opijnen et al., 2009). As a result, a total of 72 sRNAs were predicted to influence bacterial fitness in specific host niches: 28 in the lung, 26 in the nasopharynx and 18 in the blood (Mann et al., 2012).

\section{Streptococcus pyogenes}

Until recently, in $S$. pyogenes (GAS) a low number of sRNAs had been described and reported to be involved in the control of pathogenesis (PEL, FasX, RivX, and CRISPR; Kreikemeyer et al., 2001; Mangold et al., 2004; Roberts and Scott, 2007; Deltcheva et al., 2011). A bioinformatics screening using sRNAPredict2, identified 42 putative sRNA genes in GAS (Livny et al., 2006). However, the three sRNAs already known at the time (PEL, FasX, RivX) were not included. Since then, several whole genome expression screenings have been undertaken to allow a more comprehensive view of the sRNA landscape in GAS.

In MGAS2221, representing the highly virulent M1T1 GAS clone, a custom whole genome intergenic tiling array approach was used to detect sRNAs expressed in the exponential phase of growth in complex medium (Perez et al., 2009). From 40 putative sRNAs identified in this study, only seven had been detected in the previous sRNAPredict 2 study (Livny et al., 2006). Additionally to the sRNA genes, 13 small RNA candidates were identified with cis-regulatory or other typical RNA functions, including seven riboswitches and two CRISPR elements. Sixteen sRNAs and four examples of the other small RNAs (CRISPR1 , the riboswitches metK2 and serS, and 4.5S RNA, the RNA component of the signal recognition particle) were verified by Northern blot analyses. Sequence conservation over GAS genomes was tested with all 75 sRNA genes detected in the tiling array and the former bioinformatics study. Twelve sequenced GAS genomes were used for the analysis and a majority of 62 sRNAs was present in all of the genomes tested (Perez et al., 2009). 
In a similar study our laboratory identifed sRNA genes in GAS M49 (Patenge et al., 2012). Whole genome intergenic tiling arrays were used to detect transcriptional activity throughout growth in chemical defined media (CDM). In this screen, 55 putative sRNA genes were detected. Of those, 42 sRNAs were novel, but for 14 of the novel sRNA candidates a function could be predicted using the Rfam database (Griffiths-Jones et al., 2003), including several cis-regulatory RNAs, one tmRNA, an endoribonuclease (bacterial RNase P), and the RNA subunit 4.5S RNA of the SRP. Conservation of the sRNA genes was high. From 55 sRNAs, 53 were present in all GAS serotypes tested by BLAST analyses. For six sRNA candidates, the transcriptional start site was determined by $5^{\prime}$ RACE, the expression was validated by RTPCR and Northern blot analysis, and expression patterns were compared between growth phases and with growth in complex medium. The data from the tiling arrays were compared to the results of two bioinformatics prediction programs, MOSES (Raasch et al., 2010), and sRNAScanner (Sridhar et al., 2010). The modular sequence suite (MOSES) was developed, because of the high demand to combine various sRNA prediction modes in one convenient software tool, to achieve a higher reliability of the predicted data (Figure 2). In accordance with the sRNA screens in streptococci described above, the overlap between the expression results and the computer predictions was very low.
Computational screening, followed by validation of expression employing Northern blot and RT-PCR, was performed in the M3 serotype strain MGAS315 (Tesorero et al., 2013). To optimize the accuracy of the bioinformatics approach, three computational algorithms were combined: sRNAPredict (Livny et al., 2006), eQRNA (Rivas and Eddy, 2001), and RNAz (Washietl et al., 2005). All candidates that were predicted by any two of the algorithms were considered sRNA candidates. Sequences located directly upstream of ORFs were considered cis-regulatory elements and excluded from further analysis. In the exponential growth phase, 14 sRNAs were detected by Northern blot analysis: FasX, the sagA transcript, and 12 novel sRNAs. Further investigation by RNAseq and sequence analyses revealed that three of those were not trans-acting sRNA. Two were cis-regulatory elements and one appeared to be the bacterial ribonuclease P. Another two sRNAs had been detected in previous screens (Perez et al., 2009; Patenge et al., 2012), seven sRNA candidates represented novel putative trans-acting sRNAs.

Differential RNA sequencing (dRNAseq) has been recently introduced in a study of $H$. pylori (Sharma et al., 2010). The method allows the detection of transcriptional start sites and has been proved a powerful tool for the detection of small transcripts, including sRNAs. In GAS SF370, a M1 serotype, dRNAseq has been used to screen specifically for the expression of CRISPR

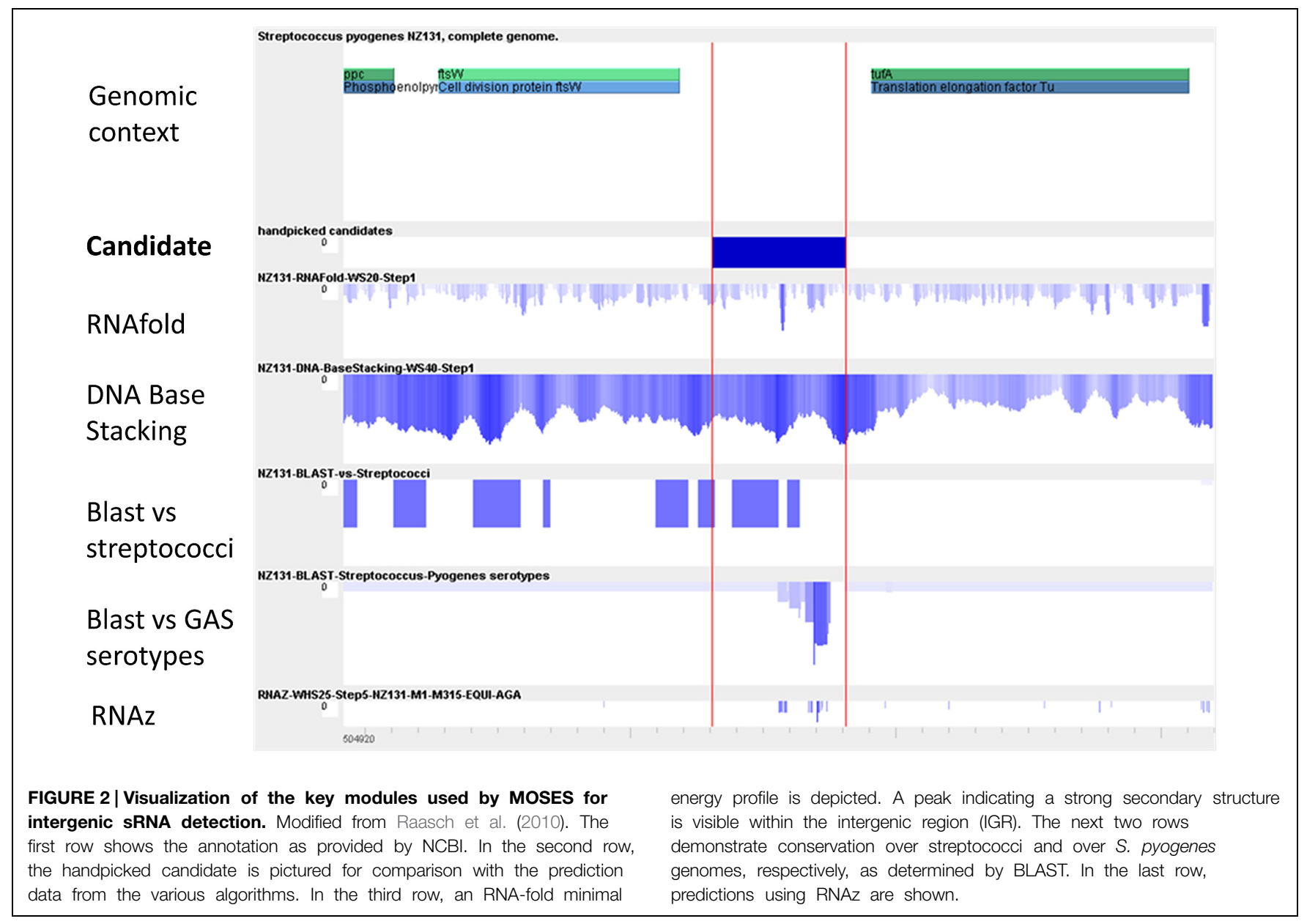


elements in GAS. This approach led to the identification of a novel class of RNAs, trans-activating CRISPR RNA (tracrRNA), which includes sequences complementary to the repeat regions of crRNAs and is involved in their maturation (Deltcheva et al., 2011).

\section{Oral Streptococci}

Posttranscriptional gene regulation in oral bacterial species has been recently reviewed (Merritt et al., 2014). With a bioinformatics tool developed for the kingdom-wide prediction and functional annotation of bacterial sRNA genes, SIPHT [sRNA identification protocol using high-throughput technologies, (Livny et al., 2008)] 18 sRNA genes were predicted in S. mutans and 34 sRNA genes in S. sanguinis. To date, no functional information is available for those putative sRNA genes. As described in the chapter about S. pneumoniae, the strong conservation of $\mathrm{CiaR}$ and $\mathrm{CiaR}$ activated promoters among streptococci was exploited to identify csRNAs in many species including oral streptococci (Halfmann et al., 2007): 3 in S. mutans, 6 in S. gordonii, 6 in S. sanguinis, 5 in S. oralis, and 5 in S. mitis strain B6 and 2 in strain SF100. Expression of the csRNAs was further verified by Northern blot analysis in S. mitis, S. oralis, and S. sanguinis. The functional mechanism of the csRNAs in oral streptococci needs further investigation.

In $S$. mutans the presence of microRNA-size small RNAs (msRNAs) has been analyzed by a deep sequencing approach (Lee and Hong, 2012). More than 900 putative msRNAs could be detected with a size of 15-26 nt. From the candidates with the highest abundance, seven were validated by qRT-PCR. Even though the function of those msRNAs is still cryptic, they might play a role in msRNA gene expression regulation or may be secreted into the surrounding saliva and take part in inter-species regulatory processes by influencing host gene expression (Lee and Hong, 2012).

Members of the oral microbiome are highly dependent on the availability of carbohydrates. Uptake systems and carbohydrate catabolic pathways are strictly regulated by the carbon catabolite repression, which is controlled in $S$. mutans by the catabolite control protein A (CcpA; Abranches et al., 2008). Differential expression of coding genes and of RNAz predicted sRNAs in response to carbohydrate availability was investigated by an RNAseq approach in S. mutans UA159 (WT) and TW1 (ccpA mutant) strains (Zeng et al., 2013). By comparing the two strains and growth conditions in the presence of glucose versus galactose, 10 sRNAs were found to be differentially expressed under these conditions. The function and relevance of these sRNA candidates needs to be determined.

In S. mutans UA159 another bioinformatics approach using four different programs, sRNAPredict (Livny et al., 2005), sRNASVM (Saha and Raghava, 2006), SIPHT (Livny et al., 2008), and "Oral Pathogens Non-Coding Small RNA Prediction" (www.oralgen.lanl.gov/_index.html), led to the detection of 334 sequences, 40 of which were predicted by at least two of the programs. In this study, only the L10-Leader was characterized further and found to be highly abundant in S. mutans UA159 by Northern blot analyses.

\section{Streptococcus suis}

A differential RNA-sequencing approach has been used to identify sRNAs from S. suis (Wu et al., 2014). To understand adaptive transcriptional regulation in $S$. suis strain $\mathrm{P} 1 / 7$ was grown in rich medium, pig blood, or cerebrospinal fluid, and RNAseq was performed. Twenty nine sRNAs were identified. Conservation of 10 sRNAs was shown in other Strepotcoccus species. Five sRNAs were functionally characterized. Deletion of the sRNA candidates did attenuate virulence of the mutants in a zebrafish infection model. Deletion of three sRNAs led to a higher sensitivity toward killing by pig blood. The respective sRNA genes were influencing the expression of several virulence factor genes, including genes involved in capsule synthesis (Wu et al., 2014).

\section{Streptococcus agalactiae}

As described above, a variety of different in silico sRNA prediction tools is available, based on a combination of features including sequence homologies, secondary structure predictions, calculation of stability, prediction of transcriptional start sites, and detection of rho-independent termination sites. The methods employed so far were not suited to predict antisense-RNAs (asRNAs) from genomic data. However, transcriptome data from several genera implicated that antisense transcriptional activity is common in bacteria and is likely to play a role in virulence control (Toledo-Arana et al., 2009; Lorenz et al., 2010; Sharma et al., 2010). In a study from Pichon et al. (2012) an algorithm was developed that allows the prediction of sRNAs as well as asRNAs. The method is based on the detection of RITassociated signatures. RIT is a recognition site for sRNA-binding proteins involved in the termination process of sRNA genes in E. coli, which is also found in Gram-positive bacteria (Pichon and Felden, 2005). From 197 predicted sRNAs in S. agalactiae NEM316, 26 were validated by RT-PCR and 10 of those showed a strong signal in Northern blot analyses. Genomic comparison showed that none of the sRNAs detected in S. agalactiae with this screening method were present in $S$. pyogenes, implying high species specificity. In overexpression experiments, three of the candidate RNAs could be shown to regulate the gene expression of adjacent target genes (Pichon et al., 2012).

\section{Conclusion}

Over the last decade, a growing number of sRNA screens both computational and experimental has been performed in streptococci. Taken together, an approximate number of at least 100 sRNAs should be expected per genome (Table 1). It is likely that more sophisticated techniques will uncover even more relevant small RNA molecules, because it is estimated that there are several 
100 sRNAs per bacterial genome. The size of the determined sRNAs lies between 40 and $500 \mathrm{nt}$, which is in accordance with the results from Gram-negative genera (Storz et al., 2011). Sequence comparisons revealed that streptococcal sRNAs are highly conserved between closely related organisms on the genus or species level and that some are conserved over streptococci. In contrast to Gram-negative examples, sRNAs are not conserved over rather unrelated Gram-positive genera. Exceptions are the small house keeping RNAs, including tmRNA and 4.5S RNA, with defined functions different from gene expression regulation.

In all species discussed here, the overlap between expression data and bioinformatics prediction data sets was low. Beside the issue of false positive predictions from both approaches, there are several reasons for this phenomenon. While an efficient prediction algorithm could principally detect every sRNA gene within a given genome due to its sequence and structural features, experimental screens are always dependent on the expression of a given sRNA. Expression - and therefore sRNA detection - depends on the strain, growth conditions, growth phase, availability of certain metabolites, or the presence of stress, or other stimulatory signals. For example, in $S$. pyogenes, the overlap between the results of two different tiling array screens were low, due to expression differences between the $M$ serotypes used and the growth conditions analyzed in the respective studies (Perez et al., 2009; Patenge et al., 2012). Additionally, the sRNA gene expression is required to reach at least the detection level of the technique employed. Many of the screens discussed here were using genomic tiling arrays or were combining bioinformatics prediction with RT-PCR or Northern blot analyses. With all approaches discussed, no initiation or termination sites can be determined. Thus, the screens were usually accompanied by further computational analyses, e.g., promoter prediction programs and rho-independent terminator prediction.

An answer to the limitations of these methods is the application of high throughput screening methods like next generation sequencing, which become more and more available and affordable. With deep sequencing approaches, a high number of conditions can be studied in parallel by simply pooling the respective samples. A demonstrative example is the exploration of the Salmonella transcriptional landscape (Kroger et al., 2012). CRISPR expression in S. pyogenes (Deltcheva et al., 2011) and the adaptive responses of the transcriptome in S. suis (Wu et al., 2014) have been investigated using dRNAseq. This technique allows the mapping of transcriptional start sites and distinguishes native RNA species from their mature forms (Sharma et al., 2010). It is used for the annotation of

\section{References}

Abranches, J., Nascimento, M. M., Zeng, L., Browngardt, C. M., Wen, Z. T., Rivera, M. F., et al. (2008). CcpA regulates central metabolism and virulence gene expression in Streptococcus mutans. J. Bacteriol. 190, 2340-2349. doi: 10.1261/rna.027359.111

Acebo, P., Martin-Galiano, A. J., Navarro, S., Zaballos, A., and Amblar, M. (2012). Identification of 88 regulatory small RNAs in the TIGR4 strain
ORFs and operons and the identification of novel transcripts, including sRNAs. Therefore, the application of dRNAseq is a promising tool for the comprehensive determination of independently transcribed sRNAs in streptococci. However, the more complex the data sets become, the more challenging the data evaluation will be. An overview over the analyses of bacterial RNAseq data has been given by McClure et al. (2013).

The development of advanced bioinformatics screening methods tries to overcome the obstacles of sheer sequence comparison. The aim is to find more candidates but also to combine more specific characteristics of sRNAs for more stringent results, e.g., screening for conserved RNA secondary structures rather than conserved sequences. In the Java-based framework MOSES, several algorithms are included in one tool to consider sequence conservation and secondary structure among other specifics (Raasch et al., 2010). Tesorero et al. (2013) were screening for sRNAs in $S$. pyogenes by combining several different computational applications, sRNAPredict, RNAz, and eQRNA followed by validation of candidates by Northern blot. In the future the combinatorial approach will be supported by machine learning, allowing the algorithms to learn from data by building models throughout the screening. An overview over sRNA prediction methods and future developments is given by Li et al. (2012).

To better understand the regulatory influence of sRNAs in bacteria and specifically to understand the impact of sRNAs on the virulence in streptococci, data from transcriptional regulation and posttranscriptional regulation must be integrated. The use of publicly available expression compendia in combination with sequenced-based predictions could be used to build sRNA-target interaction models and to analyze the impact of sRNAs on the transcriptional network (Ishchukov et al., 2014). Furthermore, the host-microbe interaction could be studied by using dual-seq approaches involving streptococci and their respective hosts as has been proposed by Westermann et al. (2012).

\section{Acknowledgments}

Work in the author's laboratory was supported by grants from the Rostock University Medical Center FORUN program, and by a BMBF grant in the framework of the ERA-Net Pathogenesis 2 program (FKZ0315437B). All authors would like to acknowledge the expert technical support of Jana Normann, Aleksandra Wisniewska-Kucper, and Yvonne Humboldt. Justin Noah Kreikemeyer is acknowledged for his help with the art work.

of the human pathogen Streptococcus pneumoniae. RNA 18, 530-546. doi: 10.1261/rna.027359.111

Altschul, S. F., Gish, W., Miller, W., Myers, E. W., and Lipman, D. J. (1990). Basic local alignment search tool. J. Mol. Biol. 215, 403-410.

Babitzke, P., and Romeo, T. (2007). CsrB sRNA family: sequestration of RNA-binding regulatory proteins. Curr. Opin. Microbiol. 10, 156-163. doi: 10.1016/j.mib.2007.03.007 
Bailey, T. L., Boden, M., Buske, F. A., Frith, M., Grant, C. E., Clementi, L., et al. (2009). MEME SUITE: tools for motif discovery and searching. Nucleic Acids Res. 37, W202-W208. doi: 10.1093/nar/gkp335

Bastet, L., Dube, A., Masse, E., and Lafontaine, D. A. (2011). New insights into riboswitch regulation mechanisms. Mol. Microbiol. 80, 1148-1154. doi: 10.1111/j.1365-2958.2011.07654.x

Bisno, A. L., Rubin, F. A., Cleary, P. P., and Dale, J. B. (2005). Prospects for a group A streptococcal vaccine: rationale, feasibility, and obstacles-report of a National Institute of Allergy and Infectious Diseases workshop. Clin. Infect. Dis. 41, 1150-1156. doi: 10.1086/444505

Bouvier, M., Sharma, C. M., Mika, F., Nierhaus, K. H., and Vogel, J. (2008). Small RNA binding to 5' mRNA coding region inhibits translational initiation. Mol. Cell 32, 827-837. doi: 10.1016/j.molcel.2008.10.027

Brantl, S. (2009). Bacterial chromosome-encoded small regulatory RNAs. Future Microbiol. 4, 85-103. doi: 10.2217/17460913.4.1.85

Brantl, S. (2012). Bacterial type I toxin-antitoxin systems. RNA Biol. 9, 1488-1490. doi: $10.4161 /$ rna.23045

Brantl, S., and Bruckner, R. (2014). Small regulatory RNAs from low-GC Grampositive bacteria. RNA Biol. 11, 443-456. doi: 10.4161/rna.28036

Caldelari, I., Chao, Y., Romby, P., and Vogel, J. (2013). RNA-mediated regulation in pathogenic bacteria. Cold Spring Harb. Perspect. Med. 3, 1-21. doi: 10.1101/cshperspect.a010298

Carapetis, J. R., Steer, A. C., Mulholland, E. K., and Weber, M. (2005). The global burden of group a streptococcal diseases. Lancet Infect. Dis. 5, 685-694. doi: 10.1016/S1473-3099(05)70267-X

Crooks, G. E., Hon, G., Chandonia, J. M., and Brenner, S. E. (2004). WebLogo: a sequence logo generator. Genome Res. 14, 1188-1190. doi: 10.1101/gr.849004

Cunningham, M. W. (2008). Pathogenesis of group a streptococcal infections and their sequelae. Adv. Exp. Med. Biol. 609, 29-42. doi: 10.1007/978-0-387-7 3960-1_3

Dando, S. J., Mackay-Sim, A., Norton, R., Currie, B. J., St John, J. A., Ekberg, J. A., et al. (2014). Pathogens penetrating the central nervous system: infection pathways and the cellular and molecular mechanisms of invasion. Clin. Microbiol. Rev. 27, 691-726. doi: 10.1128/CMR.00118-13

DebRoy, S., Gebbie, M., Ramesh, A., Goodson, J. R., Cruz, M. R., van, H. A., et al. (2014). Riboswitches. A riboswitch-containing sRNA controls gene expression by sequestration of a response regulator. Science 345, 937-940. doi: 10.1126/science.1255091

Deltcheva, E., Chylinski, K., Sharma, C. M., Gonzales, K., Chao, Y., Pirzada, Z. A., et al. (2011). CRISPR RNA maturation by trans-encoded small RNA and host factor RNase III. Nature 471, 602-607. doi: 10.1038/nature09886

Edwards, M. S., Rench, M. A., Palazzi, D. L., and Baker, C. J. (2005). Group b streptococcal colonization and serotype-specific immunity in healthy elderly persons. Clin. Infect. Dis. 40, 352-357. doi: 10.1086/426820

Facklam, R. (2002). What happened to the streptococci: overview of taxonomic and nomenclature changes. Clin. Microbiol. Rev. 15, 613-630. doi: 10.1128/CMR.15.4.613-630.2002

Fiedler, T., Sugareva, V., Patenge, N., and Kreikemeyer, B. (2010). Insights into Streptococcus pyogenes pathogenesis from transcriptome studies. Future Microbiol. 5, 1675-1694. doi: 10.2217/fmb.10.128

Frohlich, K. S., and Vogel, J. (2009). Activation of gene expression by small RNA. Curr. Opin. Microbiol. 12, 674-682. doi: 10.1016/j.mib.2009.09.009

Fulde, M., and Valentin-Weigand, P. (2013). Epidemiology and pathogenicity of zoonotic streptococci. Curr. Top. Microbiol. Immunol. 368, 49-81. doi: 10.1007/82_2012_277

Gamez, G., and Hammerschmidt, S. (2012). Combat pneumococcal infections: adhesins as candidates for protein-based vaccine development. Curr. Drug Targets. 13, 323-337. doi: 10.2174/138945012799424697

Gibbs, R. S., Schrag, S., and Schuchat, A. (2004). Perinatal infections due to group B streptococci. Obstet. Gynecol. 104, 1062-1076. doi: 10.1097/01.AOG.0000144128.03913.c2

Gogol, E. B., Rhodius, V. A., Papenfort, K., Vogel, J., and Gross, C. A. (2011). Small RNAs endow a transcriptional activator with essential repressor functions for single-tier control of a global stress regulon. Proc. Natl. Acad. Sci. U.S.A. 108, 12875-12880. doi: 10.1073/pnas.1109379108

Gorke, B., and Vogel, J. (2008). Noncoding RNA control of the making and breaking of sugars. Genes Dev. 22, 2914-2925. doi: 10.1101/gad.1717808
Gottesman, S., McCullen, C. A., Guillier, M., Vanderpool, C. K., Majdalani, N., Benhammou, J., et al. (2006). Small RNA regulators and the bacterial response to stress. Cold Spring Harb. Symp. Quant. Biol. 71, 1-11. doi: $10.1101 /$ sqb.2006.71.016

Griffiths-Jones, S., Bateman, A., Marshall, M., Khanna, A., and Eddy, S. R. (2003). Rfam: an RNA family database. Nucleic Acids Res. 31, 439-441. doi: $10.1093 / \mathrm{nar} / \mathrm{gkg} 006$

Halfmann, A., Kovacs, M., Hakenbeck, R., and Bruckner, R. (2007). Identification of the genes directly controlled by the response regulator CiaR in Streptococcus pneumoniae: five out of 15 promoters drive expression of small non-coding RNAs. Mol. Microbiol. 66, 110-126. doi: 10.1111/j.1365-2958.2007.05900.x

Heidrich, N., Chinali, A., Gerth, U., and Brantl, S. (2006). The small untranslated RNA SR1 from the Bacillus subtilis genome is involved in the regulation of arginine catabolism. Mol. Microbiol. 62, 520-536. doi: 10.1111/j.13652958.2006.05384.x

Heidrich, N., Moll, I., and Brantl, S. (2007). In vitro analysis of the interaction between the small RNA SR1 and its primary target ahrC mRNA. Nucleic Acids Res. 35, 4331-4346. doi: 10.1093/nar/gkm439

Hondorp, E. R., and McIver, K. S. (2007). The Mga virulence regulon: infection where the grass is greener. Mol. Microbiol. 66, 1056-1065. doi: 10.1111/j.13652958.2007.06006.X

Ishchukov, I., Wu, Y., Van, P. S., Vanderleyden, J., and Marchal, K. (2014). Inferring the relation between transcriptional and posttranscriptional regulation from expression compendia. BMC Microbiol. 14:14. doi: 10.1186/1471-2180-14-14

Johri, A. K., Lata, H., Yadav, P., Dua, M., Yang, Y., Xu, X., et al. (2013). Epidemiology of Group B Streptococcus in developing countries. Vaccine 31(Suppl. 4), D43-D45. doi: 10.1016/j.vaccine.2013.05.094

Keefe, G. P. (1997). Streptococcus agalactiae mastitis: a review. Can. Vet. J. 38, 429-437.

Kingsford, C. L., Ayanbule, K., and Salzberg, S. L. (2007). Rapid, accurate, computational discovery of Rho-independent transcription terminators illuminates their relationship to DNA uptake. Genome Biol. 8, R22. doi: 10.1186/gb-2007-8-2-r22

Klinkert, B., and Narberhaus, F. (2009). Microbial thermosensors. Cell Mol. Life Sci. 66, 2661-2676. doi: 10.1007/s00018-009-0041-3

Kreikemeyer, B., Boyle, M. D., Buttaro, B. A., Heinemann, M., and Podbielski, A. (2001). Group A streptococcal growth phase-associated virulence factor regulation by a novel operon (Fas) with homologies to two-component-type regulators requires a small RNA molecule. Mol. Microbiol. 39, 392-406. doi: 10.1046/j.1365-2958.2001.02226.x

Kreikemeyer, B., Gamez, G., Margarit, I., Giard, J. C., Hammerschmidt, S., Hartke, A., et al. (2011). Genomic organization, structure, regulation and pathogenic role of pilus constituents in major pathogenic Streptococci and Enterococci. Int. J. Med. Microbiol. 301, 240-251. doi: 10.1016/j.ijmm.2010.09.003

Kreikemeyer, B., McIver, K. S., and Podbielski, A. (2003). Virulence factor regulation and regulatory networks in Streptococcus pyogenes and their impact on pathogen-host interactions. Trends Microbiol. 11, 224-232. doi: 10.1016/S0966-842X(03)00098-2

Kroger, C., Dillon, S. C., Cameron, A. D., Papenfort, K., Sivasankaran, S. K., Hokamp, K., et al. (2012). The transcriptional landscape and small RNAs of Salmonella enterica serovar Typhimurium. Proc. Natl. Acad. Sci. U.S.A. 109, E1277-E1286. doi: 10.1073/pnas.1201061109

Krzysciak, W., Pluskwa, K. K., Jurczak, A., and Koscielniak, D. (2013). The pathogenicity of the Streptococcus genus. Eur. J. Clin. Microbiol. Infect. Dis. 32, 1361-1376. doi: 10.1007/s10096-013-1914-9

Kumar, R., Shah, P., Swiatlo, E., Burgess, S. C., Lawrence, M. L., and Nanduri, B. (2010). Identification of novel non-coding small RNAs from Streptococcus pneumoniae TIGR4 using high-resolution genome tiling arrays. BMC Genomics 11:350. doi: 10.1186/1471-2164-11-350

Lancefield, R. C. (1933). A serological differentiation of human and other groups of hemolytic streptococci. J. Exp. Med. 57, 571-595. doi: 10.1084/jem.57.4.571

Lasa, I., Toledo-Arana, A., and Gingeras, T. R. (2012). An effort to make sense of antisense transcription in bacteria. RNA Biol. 9, 1039-1044. doi: 10.4161/rna.21167

Le, R. A., and Charpentier, E. (2012). Small RNAs in streptococci. RNA Biol. 9, 414-426. doi: 10.4161/rna.20104 
Lee, H. J., and Hong, S. H. (2012). Analysis of microRNA-size, small RNAs in Streptococcus mutans by deep sequencing. FEMS Microbiol. Lett. 326, 131-136. doi: 10.1111/j.1574-6968.2011.02441.x

Li, W., Ying, X., Lu, Q., and Chen, L. (2012). Predicting sRNAs and their targets in bacteria. Genomics Proteomics Bioinform. 10, 276-284. doi: 10.1016/j.gpb.2012.09.004

Lindahl, G., Stalhammar-Carlemalm, M., and Areschoug, T. (2005). Surface proteins of Streptococcus agalactiae and related proteins in other bacterial pathogens. Clin. Microbiol. Rev. 18, 102-127. doi: 10.1128/CMR.18.1.102127.2005

Livny, J., Brencic, A., Lory, S., and Waldor, M. K. (2006). Identification of 17 Pseudomonas aeruginosa sRNAs and prediction of sRNA-encoding genes in 10 diverse pathogens using the bioinformatic tool sRNAPredict2. Nucleic Acids Res. 34, 3484-3493. doi: 10.1093/nar/gkl453

Livny, J., Fogel, M. A., Davis, B. M., and Waldor, M. K. (2005). sRNAPredict: an integrative computational approach to identify sRNAs in bacterial genomes. Nucleic Acids Res. 33, 4096-4105. doi: 10.1093/nar/gki715

Livny, J., Teonadi, H., Livny, M., and Waldor, M. K. (2008). High-throughput, kingdom-wide prediction and annotation of bacterial non-coding RNAs. PLoS ONE. 3:e3197. doi: 10.1371/journal.pone.0003197

Logan, L. K., McAuley, J. B., and Shulman, S. T. (2012). Macrolide treatment failure in streptococcal pharyngitis resulting in acute rheumatic fever. Pediatrics 129 , e798-e802. doi: 10.1542/peds.2011-1198

Lorenz, C., Gesell, T., Zimmermann, B., Schoeberl, U., Bilusic, I., Rajkowitsch, L., et al. (2010). Genomic SELEX for Hfq-binding RNAs identifies genomic aptamers predominantly in antisense transcripts. Nucleic Acids Res. 38, 37943808. doi: $10.1093 /$ nar/gkq032

Lybecker, M., Bilusic, I., and Raghavan, R. (2014). Pervasive transcription: detecting functional RNAs in bacteria. Transcription. 5, e944039. doi: $10.4161 / 21541272.2014 .944039$

Mangold, M., Siller, M., Roppenser, B., Vlaminckx, B. J., Penfound, T. A., Klein, R., et al. (2004). Synthesis of group A streptococcal virulence factors is controlled by a regulatory RNA molecule. Mol. Microbiol. 53, 1515-1527. doi: $10.1111 / j .1365-2958.2004 .04222 . x$

Mann, B., van, O. T., Wang, J., Obert, C., Wang, Y. D., Carter, R., et al. (2012). Control of virulence by small RNAs in Streptococcus pneumoniae. PLoS Pathog. 8:e1002788. doi: 10.1371/journal.ppat.1002788

Marx, P., Nuhn, M., Kovacs, M., Hakenbeck, R., and Bruckner, R. (2010). Identification of genes for small non-coding RNAs that belong to the regulon of the two-component regulatory system CiaRH in Streptococcus. BMC Genomics 11:661. doi: 10.1186/1471-2164-11-661

McClure, R., Balasubramanian, D., Sun, Y., Bobrovskyy, M., Sumby, P., Genco, C. A., et al. (2013). Computational analysis of bacterial RNA-Seq data. Nucleic Acids Res. 41:e140. doi: 10.1093/nar/gkt444

McIver, K. S. (2009). Stand-alone response regulators controlling global virulence networks in streptococcus pyogenes. Contrib. Microbiol. 16, 103-119. doi: $10.1159 / 000219375$

Mellin, J. R., Koutero, M., Dar, D., Nahori, M. A., Sorek, R., and Cossart, P. (2014). Riboswitches. Sequestration of a two-component response regulator by a riboswitch-regulated noncoding RNA. Science 345, 940-943. doi: $10.1126 /$ science. 1255083

Merritt, J., Chen, Z., Liu, N., and Kreth, J. (2014). Posttranscriptional regulation of oral bacterial adaptive responses. Curr. Oral Health Rep. 1, 50-58. doi: 10.1007/s40496-013-0005-4

Mika, F., and Hengge, R. (2013). Small regulatory RNAs in the control of motility and biofilm formation in E. coli and Salmonella. Int. J. Mol. Sci. 14, 4560-4579. doi: $10.3390 /$ ijms 14034560

Miller, E. W., Cao, T. N., Pflughoeft, K. J., and Sumby, P. (2014). RNAmediated regulation in Gram-positive pathogens: an overview punctuated with examples from the group a Streptococcus. Mol. Microbiol. 94, 9-20. doi: $10.1111 / \mathrm{mmi} .12742$

Mraheil, M. A., Billion, A., Kuenne, C., Pischimarov, J., Kreikemeyer, B., Engelmann, S., et al. (2010). Comparative genome-wide analysis of small RNAs of major Gram-positive pathogens: from identification to application. Microb. Biotechnol. 3, 658-676. doi: 10.1111/j.1751-7915.2010.00171.x

Narberhaus, F., and Vogel, J. (2009). Regulatory RNAs in prokaryotes: here, there and everywhere. Mol. Microbiol. 74, 261-269. doi: 10.1111/j.13652958.2009.06869.x
Nawrocki, E. P., Burge, S. W., Bateman, A., Daub, J., Eberhardt, R. Y., Eddy, S. R., et al. (2015). Rfam 12.0: updates to the RNA families database. Nucleic Acids Res. 43, D130-D137. doi: 10.1093/nar/gku1063

Opijnen, T. V., Bodi, K. L., and Camilli, A. (2009). Tn-seq: high-throughput parallel sequencing for fitness and genetic interaction studies in microorganisms. Nat. Methods 6, 767-772. doi: 10.1038/nmeth.1377

Papenfort, K., and Vogel, J. (2009). Multiple target regulation by small noncoding RNAs rewires gene expression at the post-transcriptional level. Res. Microbiol. 160, 278-287. doi: 10.1016/j.resmic.2009.03.004

Papenfort, K., and Vogel, J. (2010). Regulatory RNA in bacterial pathogens. Cell Host. Microbe 8, 116-127. doi: 10.1016/j.chom.2010.06.008

Patenge, N., Billion, A., Raasch, P., Normann, J., Wisniewska-Kucper, A., Retey, J., et al. (2012). Identification of novel growth phase- and media-dependent small non-coding RNAs in Streptococcus pyogenes M49 using intergenic tiling arrays. BMC Genomics 13:550. doi: 10.1186/1471-2164-13-550

Patenge, N., Fiedler, T., and Kreikemeyer, B. (2013). Common regulators of virulence in streptococci. Curr. Top. Microbiol. Immunol. 368, 111-153. doi: 10.1007/82_2012_295

Peng, Y., Curtis, J. E., Fang, X., and Woodson, S. A. (2014). Structural model of an mRNA in complex with the bacterial chaperone Hfq. Proc. Natl. Acad. Sci. U.S.A. 111, 17134-17139. doi: 10.1073/pnas.1410114111

Perez, N., Trevino, J., Liu, Z., Ho, S. C., Babitzke, P., and Sumby, P. (2009). A genome-wide analysis of small regulatory RNAs in the human pathogen group A Streptococcus. PLoS ONE. 4:e7668. doi: 10.1371/journal.pone.0007668

Pichon, C., du, M. L., Caliot, M. E., Trieu-Cuot, P., and Le, B. C. (2012). An in silico model for identification of small RNAs in whole bacterial genomes: characterization of antisense RNAs in pathogenic Escherichia coli and Streptococcus agalactiae strains. Nucleic Acids Res. 40, 2846-2861. doi: 10.1093/nar/gkr1141

Pichon, C., and Felden, B. (2005). Small RNA genes expressed from Staphylococcus aureus genomic and pathogenicity islands with specific expression among pathogenic strains. Proc. Natl. Acad. Sci. U.S.A. 102, 14249-14254. doi: 10.1073/pnas.0503838102

Podkaminski, D., and Vogel, J. (2010). Small RNAs promote mRNA stability to activate the synthesis of virulence factors. Mol. Microbiol. 78, 1327-1331. doi: $10.1111 / j .1365-2958.2010 .07428 . x$

Raasch, P., Schmitz, U., Patenge, N., Vera, J., Kreikemeyer, B., and Wolkenhauer, O. (2010). Non-coding RNA detection methods combined to improve usability, reproducibility and precision. BMC Bioinform. 11:491. doi: 10.1186/1471-210511-491

Rajagopal, L. (2009). Understanding the regulation of Group B streptococcal virulence factors. Future Microbiol. 4, 201-221. doi: 10.2217/17460913.4.2.201

Ralph, A. P., and Carapetis, J. R. (2013). Group a streptococcal diseases and their global burden. Curr. Top. Microbiol. Immunol. 368, 1-27. doi: 10.1007/82_2012_280

Rieder, R., Reinhardt, R., Sharma, C., and Vogel, J. (2012). Experimental tools to identify RNA-protein interactions in Helicobacter pylori. RNA Biol. 9, 250-531. doi: 10.4161/rna.20331

Rivas, E., and Eddy, S. R. (2001). Noncoding RNA gene detection using comparative sequence analysis. BMC Bioinform. 2:8. doi: 10.1186/1471-2105$2-8$

Roberts, S. A., and Scott, J. R. (2007). RivR and the small RNA RivX: the missing links between the CovR regulatory cascade and the Mga regulon. Mol. Microbiol. 66, 1506-1522. doi: 10.1111/j.1365-2958.2007. 06015.x

Saha, S., and Raghava, G. P. (2006). VICMpred: an SVM-based method for the prediction of functional proteins of Gram-negative bacteria using amino acid patterns and composition. Genomics Proteomics Bioinformatics 4, 42-47. doi: $10.1016 / \mathrm{S} 1672-0229(06) 60015-6$

Serganov, A., and Nudler, E. (2013). A decade of riboswitches. Cell 152, 17-24. doi: 10.1016/j.cell.2012.12.024

Sharma, C. M., Darfeuille, F., Plantinga, T. H., and Vogel, J. (2007). A small RNA regulates multiple $\mathrm{ABC}$ transporter mRNAs by targeting $\mathrm{C} / \mathrm{A}$-rich elements inside and upstream of ribosome-binding sites. Genes Dev. 21, 2804-2817. doi: 10.1101/gad. 447207

Sharma, C. M., Hoffmann, S., Darfeuille, F., Reignier, J., Findeiss, S., Sittka, A., et al. (2010). The primary transcriptome of the major human pathogen Helicobacter pylori. Nature 464, 250-255. doi: 10.1038/nature08756 
Sharma, C. M., Papenfort, K., Pernitzsch, S. R., Mollenkopf, H. J., Hinton, J. C., and Vogel, J. (2011). Pervasive post-transcriptional control of genes involved in amino acid metabolism by the Hfq-dependent GcvB small RNA. Mol. Microbiol. 81, 1144-1165. doi: 10.1111/j.1365-2958.2011.07751.x

Sridhar, J., Sambaturu, N., Sabarinathan, R., Ou, H. Y., Deng, Z., Sekar, K., et al. (2010). sRNAscanner: a computational tool for intergenic small RNA detection in bacterial genomes. PLoS ONE 5:e11970. doi: 10.1371/journal.pone.00 11970

Storz, G., Vogel, J., and Wassarman, K. M. (2011). Regulation by small RNAs in bacteria: expanding frontiers. Mol. Cell 43, 880-891. doi: 10.1016/j.molcel.2011.08.022

Tesorero, R. A., Yu, N., Wright, J. O., Svencionis, J. P., Cheng, Q., Kim, J. H., et al. (2013). Novel regulatory small RNAs in Streptococcus pyogenes. PLoS ONE 8:e64021. doi: 10.1371/journal.pone.0064021

Thomason, M. K., and Storz, G. (2010). Bacterial antisense RNAs: how many are there, and what are they doing? Annu. Rev. Genet. 44, 167-188. doi: 10.1146/annurev-genet-102209-163523

Tjaden, B., Goodwin, S. S., Opdyke, J. A., Guillier, M., Fu, D. X., Gottesman, S., et al. (2006). Target prediction for small, noncoding RNAs in bacteria. Nucleic Acids Res. 34, 2791-2802. doi: 10.1093/nar/gkl356

Toledo-Arana, A., Dussurget, O., Nikitas, G., Sesto, N., Guet-Revillet, H., Balestrino, D., et al. (2009). The Listeria transcriptional landscape from saprophytism to virulence. Nature 459, 950-956. doi: 10.1038/nature 08080

Tsui, H. C., Mukherjee, D., Ray, V. A., Sham, L. T., Feig, A. L., and Winkler, M. E. (2010). Identification and characterization of noncoding small RNAs in Streptococcus pneumoniae serotype 2 strain D39. J. Bacteriol. 192, 264-279. doi: 10.1128/JB.01204-09

Valentin-Hansen, P., Eriksen, M., and Udesen, C. (2004). The bacterial Sm-like protein Hfq: a key player in RNA transactions. Mol. Microbiol. 51, 1525-1533. doi: 10.1111/j.1365-2958.2003.03935.x

Vanderpool, C. K., and Gottesman, S. (2005). Noncoding RNAs at the membrane. Nat. Struct. Mol. Biol. 12, 285-286. doi: 10.1038/nsmb0405-285
Walker, M. J., Barnett, T. C., McArthur, J. D., Cole, J. N., Gillen, C. M., Henningham, A., et al. (2014). Disease manifestations and pathogenic mechanisms of group a Streptococcus. Clin. Microbiol. Rev. 27, 264-301. doi: 10.1128/CMR.00101-13

Washietl, S., Hofacker, I. L., and Stadler, P. F. (2005). Fast and reliable prediction of noncoding RNAs. Proc. Natl. Acad. Sci. U.S.A. 102, 2454-2459. doi: 10.1073/pnas.0409169102

Waters, L. S., and Storz, G. (2009). Regulatory RNAs in bacteria. Cell 136, 615-628. doi: 10.1016/j.cell.2009.01.043

Westermann, A. J., Gorski, S. A., and Vogel, J. (2012). Dual RNA-seq of pathogen and host. Nat. Rev. Microbiol. 10, 618-630. doi: 10.1038/nrmicro2852

Wu, Z., Wu, C., Shao, J., Zhu, Z., Wang, W., Zhang, W., et al. (2014). The Streptococcus suis transcriptional landscape reveals adaptation mechanisms in pig blood and cerebrospinal fluid. RNA 20, 882-898. doi: 10.1261/rna.041822.113

Yu, H., Jing, H., Chen, Z., Zheng, H., Zhu, X., Wang, H., et al. (2006). Human Streptococcus suis outbreak, Sichuan, China. Emerg. Infect. Dis. 12, 914-920. doi: 10.3201/eid1206.051194

Zeng, L., Choi, S. C., Danko, C. G., Siepel, A., Stanhope, M. J., and Burne, R. A. (2013). Gene regulation by CcpA and catabolite repression explored by RNA-Seq in Streptococcus mutans. PLoS ONE. 8:e60465. doi: 10.1371/journal.pone.0060465

Conflict of Interest Statement: The authors declare that the research was conducted in the absence of any commercial or financial relationships that could be construed as a potential conflict of interest.

Copyright (c) 2015 Patenge, Pappesch, Khani and Kreikemeyer. This is an open-access article distributed under the terms of the Creative Commons Attribution License (CC BY). The use, distribution or reproduction in other forums is permitted, provided the original author(s) or licensor are credited and that the original publication in this journal is cited, in accordance with accepted academic practice. No use, distribution or reproduction is permitted which does not comply with these terms. 